\title{
The Experience of the Passage of Time as Narrated by Women With Breast Cancer: A Qualitative Study
}

\author{
Ahmad Kalateh Sadati ${ }^{1,} ;$ Farnaz Rahnavard ${ }^{2}$; Najmeh Ebrahimzadeh $^{3}$; Najmeh Maharloei $^{1}$ \\ ${ }^{1}$ Health Policy Research Center, Shiraz University of Medical Sciences, Shiraz, IR Iran \\ ${ }^{2}$ Laparoscopy Research Center, Shiraz University of Medical Sciences, Shiraz, IR Iran \\ 3 Shiraz Burn Research Center, Shiraz University of Medical Sciences, Shiraz, IR Iran \\ ${ }^{*}$ Corresponding author: Ahmad Kalateh Sadati, Health Policy Research Center, Shiraz University of Medical Sciences, Shiraz, IR Iran. Tel: +98-7132309615, Fax: +98-7132309615, \\ E-mail: asadati@sums.ac.ir
}

Received: November 22, 2014; Revised: January 7, 2015; Accepted: May 15, 2015

\begin{abstract}
Background: Breast cancer is closely linked with the quality of passage of time by the patient.
Objectives: The purpose of this study was to explore the experience of the passage of time in narratives of women with breast cancer. Patients and Methods: Data were collected through in-depth interviews with 8 women after mastectomy. A thematic method based on the qualitative research was used to explore the meaningful themes.

Results: The results obtained revealed that the story of passing of time involved two fluctuation modes. At the primary stages of encountering breast cancer the patients experience a chaotic time in which the first reaction was denying and disavowing the fact that they were plagued by an unexpected threat. Following this stage, the patients begin to progressively base their experience on creativity and religious coping strategies called the calmness period.

Conclusions: Passing of time is of fluctuation type. Creativity and religious context have main roles in resolving the psychological problems of women with breast cancer. Therefore, policy makers must consider planning to enrich religious beliefs in women with breast cancer.
\end{abstract}

Keywords: Breast Cancer; Passage of Time; Fluctuation; Chaotic Experience

\section{Background}

Illness is an event that can unpredictably threaten human life (1). As this event is related to death it becomes a matter of grave concern that makes individuals normally experience anxiety and apprehension on facing diseases. Although illnesses are not always associated with death, they can negatively affect and limit the patients' strength $(1,2)$. Thus, illness is an intensely personal element of human existence, which often debilitates an individual both psychologically and physically regardless of its specific aspects (2).

Breast cancer in women is life threatening and is associated with traumatic and horrific experience. It negatively affects such issues as body image, sexual relationship, suitable social contacts in feminine societies, and reproduction (1), entities that should be addressed by applying efficient coping strategies (3-8).

Illness includes a difficult experience that changes over time, and is strongly related to the patients' momentary state of mind (9).

\section{Objectives}

This study does not consider the qualitative aspect of women with breast cancer. Nevertheless, mental health studies have shown that illness is associated with timedependent fluctuations in patients' temperament (9-11). Therefore, in addition to considering coping strategies for these patients, the question asked is how such patients carry the burden of illness and what the trend of this experience would be during diagnosis and treatment of the illness.

\section{Patients and Methods}

This is a qualitative research, in which a qualitative approach including a narrative interview was used for data gathering and analysis. Narrative data were obtained through listening to patients' accounts of experiences and interpretations of an illness, treatment or care (12).

The study comprised 8 women with breast cancer who underwent surgical removal of one breast and participated in interviews. Participants were informed of the research objectives, were at liberty and made their choice to participate in the research. Moreover, their privacy was maintained regarding the interview and as the interviewer was female, the participants felt no inhibitions, or restrictions to cooperate. The participants were selected

Copyright (C)2015, Health Policy Research Center, Shiraz University of Medical Sciences. This is an open-access article distributed under the terms of the Creative Commons Attribution-NonCommercial 4.0 International License (http://creativecommons.org/licenses/by-nc/4.0/) which permits copy and redistribute the material just in noncommercial usages, provided the original work is properly cited. 
under the supervision of the general surgeon who had treated the participants after surgical mastectomy. The research process involved both internal and external validity of qualitative methodology. Data gathering was done in May 2012, and the information of the participants was shown in Table 1. To maintain ethical considerations real names of the participants were replaced with illusory names.

\begin{tabular}{|c|c|c|c|c|}
\hline $\begin{array}{l}\text { Imitation } \\
\text { Name }\end{array}$ & Age $(y)$ & $\begin{array}{l}\text { Number(s) } \\
\text { of Children }\end{array}$ & $\begin{array}{l}\text { Type of } \\
\text { surgery }\end{array}$ & $\begin{array}{c}\text { Date of } \\
\text { Operation }\end{array}$ \\
\hline Monir & 50 & 2 & $\mathrm{~L}$ and $\mathrm{T}$ & 2006 \\
\hline Maryam & 58 & 4 & L and T & 2007 \\
\hline Fateme & 65 & 3 & $\mathrm{R}$ and $\mathrm{T}$ & 2009 \\
\hline Ashraf & 47 & 3 & $\mathrm{~L}$ and $\mathrm{T}$ & 2011 \\
\hline Farzaneh & 33 & 2 & $\mathrm{~L}$ and $\mathrm{T}$ & 2009 \\
\hline Narges & 41 & 3 & R and T & 2011 \\
\hline Zahra & 29 & - & R and T & 2010 \\
\hline Zahra & 50 & 2 & $\mathrm{R}$ and $\mathrm{T}$ & 2008 \\
\hline
\end{tabular}

${ }^{a}$ The marital status of all the patients are married.

b Abbreviations, L: Left, R: Right, T: Total mastectomy.

The grounded theory method, introduced by Strauss and Corbin (13), was used for data analysis. Coding was done in three phases including open, axial, and selective processes. Open coding involved identifying the concepts, their information and features. The axial coding referred to the recognition of categories and their relationships. The selective coding was the process of creating theory. Poststructuralist validity methods were applied to assess the validity (14).

\section{Results}

After in-depth interviews and thorough investigation of the content, the main themes relating to the passing of time were extracted. This research explored two main categories of passage of time. The first category concerned the difficulty, hardship, inflexibility and adversity of the whole experience. This category was extracted from 11 concepts and subcategorized as open coding and axial coding processes. The second category related to hope, empowerment, perseverance, flexibility, reflexivity and experience about healing concepts of the illness. This was extracted from 9 concepts and 3 subcategories related to open and axial coding processes. Both categories showed the fluctuation form of passing of time in the patients.

\subsection{The Chaotic Period}

This represents the time related to difficulty, hardship, inflexibility and adversity. Primarily, the experience of encountering an illness helps explore the perceived complexity and difficulty through the passage of time which refers to the experience of encountering an illness which reflects the worst meanings in patients' lives. These definitions justify any denial, depression and isolation from others. When a woman encounters breast cancer, her new experiences which are especial and unique to her start to emerge. At this point, a multitude of implications would evolve and reproduce in women's mental semantic system. Initially, meaningful concepts focus on denying the illness. The patient may try to come up with any justification to deny the illness. From her point of view, breast cancer is a devastating crisis and the greatest tragedy of her life. However, as the results of the examinations are confirmed, the passage of time gradually leads the women to a chaotic stage characterized by experiencing many thoughts and behaviors that reinforce the chaotic period. Constantly crying, rejection of others, thinking about death and fate of their children, and thinking about losing their breast or hair, are among the worst concepts developed and experienced by women with breast cancer. One participant quoted:

I used to cry a lot at first, and over the first week I was very depressed. I did not study, I was not in the mood to talk to anyone, and at first I did not want the treatment, thinking that it was hard for me to accept. Yea, I thought it was the end of my life, and I was preoccupied by this idea.

Another said:

It was extremely hard for me, because the thought of losing one part of my body was too sad, when the doctor said he had to do a surgery and cut off my breast. I was very upset and was certain that nothing good would happen to me. I gave myself to God, it was extremely hard for me.

At this stage, women with breast cancer had horrible experiences associated with the idea of death, their children's fate, and their body image, while they constantly cried. They lived with uncertainty. This is a chaotic episode of time that can be extremely difficult to pass. Apparently, they were too emotionally disturbed to really understand the situation.

\subsection{Calmness Time}

Humans have creativity characteristics that help them during chaotic times (1). Women with breast cancer started thinking about treatment and cure as time passes. At this time, they had accepted the illness, and relied on a power undiscovered up until then and formulated a meaningful way that shapes a new meaning of life. This new meaning was formed based on two main sources of power: social context and personal creativity. Social context has an important role in contextualizing the new way of life. This context puts emphasis on the meanings that create new coping strategies for unpleasant and chaotic times. All of these women, according to their religious accounts, defined new meanings and goals for life and death. This is because they found themselves in a social context. Despite many changes over the past three decades, the basic relations of Iranian social context are 
regulated by a religious character. By relying on this character, all women under the study produced new meanings about life and death.

Moreover, another main power that was explored in this narrative is human creativity that helped our participants define new means and ways for passing the chaotic episode and create a new life. This creativity has a psychosocial and spiritual dimension, which opens a new window of life for women. This window changes their behaviors and beliefs about life and death. The passage of time in the period, which happens after the chaotic time is called calmness time.

The new experience of passing of time was shaped with two basic sources of power, so called social context and personal creativity, which were discovered by women with breast cancer. Social context was based on religious concepts and found to constitute many encouraging and new meaningful ideas for the participants, to find a new sense of life. This new scope helped women establish an enriched relationship to God and reproduce their life through other religious concepts, a status reported by all participants. In this connection, one of the women quoted:

Faith in God, I think, has impacted my life: my sister and her children said they had panicked when they heard about my breast cancer, but when I learnt about my illness, I did not panic at all.

Calmness time is related to personal creativity for restoring bodily damages. Since these women had one of their breasts radically excised, they used personal creativity to compensate for the loss. Despite the recommendation of the treatment team for plastic surgery, these women used their personal methods to compensate for their defects. Using wigs to cover hair loss, using a sponge to fill the breast roughs, using special bras and soft cloth are among the creativities in women for rebuilding their body.

Along with physical aspects, "repairing" the conceptual meanings of life is a crucial stage. In this theme, women with breast cancer started to create a new meaning about life enriched with hope and empowerment. One of the participants said:

I always hope, much hope! A philosopher, whose name I don't remember, was asked by a journalist about what he would write about hope? He says even if he writes 9 pages, on the last page he writes just 'hope, hope, and hope' I hope because all of life is about hope and when you have hope you can enjoy life.

\subsection{Fluctuation}

By and large, the results of this research indicate that passing of time has a fluctuation feature, which refers to the quality of the experience and events woman with breast cancer facing with. The duration of time, from encountering crisis onwards, represents a cycle. Although the cycle involves a progressive course of events, it does not follow a straight line. When a woman becomes aware of her illness, she goes through a chaotic experience; however, she enters the stage of calmness in gradual steps. An important point is the reflexivity of the experience and meaning in this endless path.

The stable conditions experienced by the patient is not long lasting, but can be addressed by enriching the themes that leads to the rebuilding story. These themes, as indicated above, are based on two sources of power and encouragement involving religious context and self-creativity. In the long run, woman with breast cancer should be living like others, creating meaningful concepts that help her get over the crisis. This situation needs a reflexive character that helps the woman achieve this new scope of life, which contains meanings and experiences of the past, present and future, as well as meaningful concepts about the self, God and living.

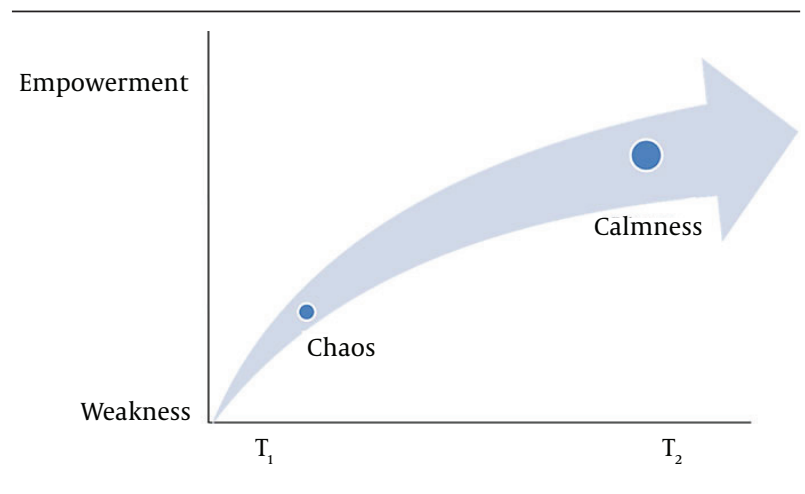

Figure 1. Passing of Time in the Experience of Women with Breast Cancer

\section{Discussion}

Passing of time is accompanied by fluctuations in attitudes of the women with breast cancer. The initial encounter of the patient with the illness is accompanied by depression and frustration. Consequently, the patient experiences the chaotic time in which she senses uncertainty and ambiguity about life and death. However, based on creativity trait, these patients try to accept this dire situation. After intensive endeavors, they experience calmness that is related to hope and recovery. In a study, Lightfoot referred to the temporal structure of stories model developed by Gergen and Gergen (15) in which the passing of time involves three major features including progressive, regressive and stable. In expression of time that includes unifying proportions, the narrative moves in a stepwise fashion toward progressive, regressive and stable stages. In the regressive trend, meanings and experiences may be represented incoherently, as in suicide cases. The stable condition is not marked by any significant changes (15). Based on the results obtained, women with breast cancer do not have a stable story every day, because they are distressed by issues such as recurrent illness, special self-care where they often do not use their hand on the side of mastectomy, consumption of drugs, annual examinations, costs of treatment, and so on. All 
participants in this research reported a dominant narrative of social problems after their surgery. Many women avoided attending feminine meetings or stadiums, or taking part in other activities such as swimming. In these social circumstances, what they psychologically experience is different from those of healthy woman. However, their experiences were found to have a reflexive character that provides some new approaches to the illness, life and death. This reflexive character should be maintained if such women desire to continue progressive experiences.

The results showed that women with breast cancer experienced two transitions of time, namely, chaotic and calmness. Chaotic time covers the duration of time that a woman with breast cancer grapples with the disease. In the course of this critical period patients experience ambiguity, difficulty and complexity. In this story, the experience of encountering an illness represents as the worst meaning in the patients' lives. These perceived meanings justify any denial, depression and isolation from others. Yet, those living with religious beliefs showed a potential for creativity. Religious context and creativity affect the women's perspectives and open up new windows in their lives, which give new meanings and experiences about life. In this research, time-related rehabilitation so called calmness time, prepares women with breast cancer fight with the new crisis and hope to conquer it. Using the religious context, personal creativity, and rebuilding meaningful concepts let them create a new approach to life. This is a hopeful and empowering form of passing of time in women with breast cancer as shown in Figure 1; T1 is the period of a difficult and hard condition that patients experience. The weak psychological status makes patient sense gloomy experiences. Nevertheless, they do not stay under such bitter conditions and it is crucial for the patients to pass through this stage. Women with breast cancer rely on their reflexivity to preserve their potential power and the significance of the religious context that help them achieve new conditions at T2, so called the time of empowerment. New lifetime needs preserving semantic coherence and concrete experiences by which women maintain their reflexive relationship with the self, God and life, as well as with past, present and future. It is important for women with breast cancer to pass through these critical times by the help of religious concepts and creativity, a coping strategy resolving problems associated with chaotic situations (1)

Other studies confirm the results of the present study particularly the role of religious beliefs as a coping strategy for women with breast cancer (1-9). Furthermore, Wittmann et al. (9) showed the concept of time awareness in this context which is increasingly important as an indicator of success in coping with mental distress caused by a life-threatening disease. In this research, women with breast cancer experience the successful passage of time in creating new conditions and define a new path for their lives.
Based on the results obtained, clinical teams such as physicians and nurses and also policy makers of health system should provide necessary conditions to fulfill the physical and spiritual needs of women with breast cancer. Policy makers play a fundamental role in drawing attention to this psycho/social need to secure the personal, institutional and economical requirements for these patients. A crucial approach to resolving the problems of such patients is to enrich their religious beliefs for passing of time easily, a process of immense importance particularly in the chaotic period.

\section{Acknowledgements}

The authors would like to express their appreciation to Dr. Kamran Bagheri Lankarani, the head of health policy research center, Shiraz University of Medical Sciences, Shiraz, Iran.

\section{Authors' Contributions}

Ahmad Kalateh Sadati: research designer, data interpreter, and preparation the manuscript. Najmeh Ebrahimzadeh and Farnaz Rahnavard: data gathering and transcribing.

\section{Financial Disclosure}

Health Policy Research center.

\section{Funding/Support}

This research was supported by Health Policy Research Center (grant No. HP 49 - 90) at Shiraz University of Medical Sciences, Shiraz, Iran.

\section{References}

1. Sadati AK, Lankarani KB, Gharibi V, Fard ME, Ebrahimzadeh $\mathrm{N}$, Tahmasebi S. Religion as an Empowerment Context in the Narrative of Women with Breast Cancer. J Religion Health. 2014;54(3):1068-79.

2. Olson AM. The Narrative Construction of Breast Cancer: Comparative Case Study of The Susan G. Komen Foundation And National Breast Cancer Coalitions'Campaign Strategies, Messages, And Effects. : Ohio University; 2005.

3. Ahmad F, Muhammad M, Abdullah AA. Religion and spirituality in coping with advanced breast cancer: perspectives from Malaysian Muslim women.J Relig Health. 2011;50(1):36-45.

4. Bredle JM, Salsman JM, Debb SM, Arnold BJ, Cella D. Spiritual Well-Being as a Component of Health-Related Quality of Life: The Functional Assessment of Chronic Illness Therapy-Spiritual Well-Being Scale (FACIT-Sp). Religions. 2011;2(4):77-94.

5. Keeley B, Wright L, Condit CM. Functions of health fatalism: fatalistic talk as face saving, uncertainty management, stress relief and sense making. Sociol Health Illn. 2009;31(5):734-47.

6. Hare M. The lived experience of breast cancer-related lymphoedema. Nurs Stand. 2000;15(7):35-9.

7. Howard AF, Bottorff JL, Balneaves LG, Grewal SK. Punjabi immigrant women's breast cancer stories. J Immigr Minor Health. 2007;9(4):269-79.

8. Urcuyo KR, Boyers AE, Carver CS, Antoni MH. Finding benefit in breast cancer: Relations with personality, coping, and concurrent well-being. Psychology \& Health. 2005;20(2):175-92.

9. Wittmann M, Vollmer T, Schweiger C, Hiddemann W. The rela- 


\section{Kalateh Sadati A et al.}

tion between the experience of time and psychological distress in patients with hematological malignancies. Palliat Support Care. 2006;4(4):357-63.

10. Hicks JW. Fifty Signs of Mental Illness: A Guide to Understanding Mental Health.: Yale Uni Press; 2005.

11. Jaffe J, Segal J, Dumke LF. Emotional and Psychological Trauma: Causes, Symptoms, Effects, and Treatment. Mental emotional trauma. 2005.
12. Holloway I, Freshwater H. Narrative Research in Nursing.UK: Blackwell; 2007.

13. Strauss AL, Corbin JM. Basics of qualitative research.: Sage Newbury Park, CA; 1990

14. Riessman CK. Narrative Analysis.New York: SAGE Pub; 1993.

15. Lightfoot C. Narrative Analysis. USA: Sage; 2004. pp. 21-37.1.2 Fantastic Self: A Study of Adolescents' Fictional Narratives, and Aesthetic Activity as Identity Work. 